\title{
Job strain, social support at work, and incidence of myocardial infarction
}

\author{
Niklas Hammar, Lars Alfredsson, Jeffrey V Johnson
}

\section{Division of Epidemiology, Institute of Environmental Medicine, Karolinska Institute, Stockholm, Sweden \\ N Hammar \\ L Alfredsson}

Department of Epidemiology, Karolinska Hospital, Stockholm, Sweden N Hammar

Division of Social and Behavioral Sciences, Department of Health Policy and Management, The Johns Hopkins School of Hygiene and Public Health, Baltimore, USA

J V Johnson

Division of Occupational Health, Department of Environmental Health Sciences, Johns Hopkins School of Public Health, Baltimore, USA J V Johnson

Correspondence to: Dr Niklas Hammar, Division of Epidemiology, Institute of Environmental Medicine, Karolinska Institutet, Box 210, S-171 77 Stockholm, Sweden.

Accepted 24 February 1998

\begin{abstract}
Objectives-The combination of high psychological job demands and low decision latitude (high job strain) has been associated with an increased risk of coronary heart disease. It has been proposed that this may also be the case for low social support at work. The aim of this study was to analyse the relations between these psychosocial factors and incidence of myocardial infarction.

Methods-Associations between psychosocial work characteristics and incidence of myocardial infarction was investigated through a population based case-control study. The study base comprised employed men and women in five Swedish counties during the years 1976-84. Cases of first myocardial infarction were identified from hospital discharge registers and death records from outside hospital, controls were selected through a random sample, and psychosocial work environment was assessed through a job exposure matrix on the basis of the occupation in the 1970 and 1975 censuses.

Results-An increased incidence of myocardial infarction was found for men and women in occupations characterised by low decision latitude. For men this increase was seen primarily in combination with high psychological demands (high job strain) and low social support at work. Younger men (30-54 years of age) in occupations with both high job strain and low social support at work had a relative risk of $1.79(95 \%$ confidence interval $(95 \% \mathrm{CI})$ 1.22 to 2.65 ) compared with subjects in low strain and high social support jobs after controlling for age, county of residence, and socioeconomic group.

Conclusions-Our results indicate that jobs characterised by low decision latitude, high job strain, or low social support at work may be associated with an increased risk of acute myocardial infarction. If these associations are causal they may be of substantial importance from the point of view of workers' health.

(Occup Environ Med 1998;55:548-553)
\end{abstract}

Keywords: job strain; social support at work; myocardial infarction

There is a growing interest in the role of the psychosocial work environment for the development of coronary heart disease. About 15 years ago a model of psychological demands and decision latitude was introduced by Karasek. ${ }^{1}$
According to this model, which has been used in several studies, a high strain job is characterised by high psychological demands in combination with low decision latitude. Schnall et al, in their review of the literature, found in most studies an increased risk of cardiovascular disease or all cause mortality for subjects in high strain occupations compared with subjects in other occupations. ${ }^{2}$ In studies where job strain has been related to coronary heart disease, a positive association has in general been found. ${ }^{3-11}$ Some of these studies, however, used information from prevalent cases or failed to control for potential confounding from factors such as smoking habits, dietary habits, and physical activity, thus complicating interpretations of causal associations of these findings. In a recent study based on the national health and nutritional examination (NHANES1) survey, high work control was associated with a low incidence of coronary heart disease, but no relation was found between job strain and coronary heart disease. ${ }^{12}$

The possible influence of social support at work on cardiovascular disease has only been investigated to a limited extent. An increased prevalence of cardiovascular disease for subjects with low social support at work and an increased overall mortality associated with low social support at work combined with job strain has been reported. ${ }^{13}{ }^{14}$ In a recent study based on a 14 year follow up of Swedish men, low social support at work, considered as an individual variable, was not strongly related to increased mortality from cardiovascular disease. ${ }^{15}$ However, workers with low social support at work combined with low work control had highly increased cardiovascular mortality. The aim of the present study was to investigate job strain and social support at work, separately and in combination, relative to incidence of myocardial infarction.

\section{Subjects and methods}

The study base comprised the population from 30 to 64 years of age in four rural Swedish counties from 1976 to 1981 and in Stockholm County from 1976 to 1984 . The relation between psychosocial work environment and myocardial infarction was studied by casecontrol methods. Cases of myocardial infarction were identified through the combined use of hospital discharge registers and death records in accordance with a method that was developed and evaluated previously. ${ }^{16}{ }^{17}$ To classify infarctions as first or recurrent events, additional information from the hospital discharge registers was used. For each case, two random controls were selected from the study 
Table 1 Number of cases of first myocardial infarction and number of controls by sex and age (unchanged type of occupation from 1970-5 with regard to decision latitude, psychological demands, or social support at work)

\begin{tabular}{|c|c|c|c|c|c|c|}
\hline \multirow[b]{2}{*}{ Age } & \multicolumn{2}{|l|}{ Men } & \multicolumn{2}{|c|}{ Women } & \multicolumn{2}{|l|}{ All } \\
\hline & Cases & Controls & Cases & Controls & Cases & Controls \\
\hline $30-44$ & 492 & 1324 & 65 & 140 & 557 & 1464 \\
\hline $45-54$ & 2255 & 6164 & 245 & 626 & 2500 & 6790 \\
\hline $55-64$ & 6086 & 17425 & 865 & 2769 & 6951 & 20194 \\
\hline All & 8833 & 24913 & 1175 & 3535 & 10008 & 28448 \\
\hline
\end{tabular}

Table 2 Relative risk (RR) for a first myocardial infarction for subjects in occupations with low* decision latitude, high psychological demands, and low social support at work compared with subjects in occupations with high decision latitude, low psychological demands, and high social support at work

\begin{tabular}{|c|c|c|c|c|}
\hline \multirow[b]{2}{*}{ Work environment factor } & \multicolumn{2}{|l|}{ Men } & \multicolumn{2}{|c|}{ Women } \\
\hline & $R R t$ & $(95 \% C I)$ & $R R$ & $(95 \% C I)$ \\
\hline \multicolumn{5}{|l|}{ Decision latitude: } \\
\hline High & 1.00 & - & 1.00 & - \\
\hline Low & 1.19 & (1.13 to 1.25$)$ & 1.44 & (1.25 to 1.65$)$ \\
\hline \multicolumn{5}{|l|}{ Psychological demands: } \\
\hline Low & 1.00 & - & 1.00 & - \\
\hline High & 0.94 & (0.89 to 0.99$)$ & 0.95 & (0.82 to 1.10$)$ \\
\hline \multicolumn{5}{|l|}{ Social support at work: } \\
\hline High & 1.00 & - & 1.00 & - \\
\hline Low & 1.15 & (1.10 to 1.22$)$ & 1.20 & (1.04 to 1.39$)$ \\
\hline
\end{tabular}

$\star$ Low defined as a score below the median, for cases and controls combined, and high defined as a score above the median.

tRR adjusted for age, county of residence, and calendar year.

base, stratified by sex, age (5-year age groups), and year of hospital admission or death of the cases. For the selection of these controls we used registers of the total population for each year throughout the study period.

Information about occupation and some other sociodemographic factors was obtained from the 1970 and the 1975 censuses by record linkage. In this linkage, $99 \%$ of the cases and the controls were found in the census data. Occupation was coded in the census data according to the Nordic modification of the three digit international standard classification of occupations. Cases and controls were classified into the socioeconomic groups unskilled and skilled manual workers and assistant, intermediate, and higher non-manual employees, on the basis of their occupation, in accordance with a method used in the Swedish 1990 census. ${ }^{18} \mathrm{~A}$ description of the identification of cases and controls as well as of the record linkage to the censuses has been given elsewhere. ${ }^{19}$

\section{WORK ENVIRONMENT}

To characterise occupational groups by psychosocial work environment, a work organisation exposure matrix (WOM) was used. The matrix has been developed by Johnson et al on the basis of information from Swedish national interview surveys carried out in 1977 and 1979 comprising a total of 12084 randomly sampled employed subjects from 25 to 74 years of age. This matrix has been described and used in previous studies. ${ }^{15}$ 20-23 Occupations, defined in accordance with the Nordic classification of occupations on the three digit level, were classified in the WOM for psychological demands, decision latitude, and social support at work. Psychological job demands was measured through two items in the National surveys: is your job hectic?, and is your job psychologically demanding?. Decision latitude was measured through 11 items including different aspects of the work situation: monotony, possibilities to learn new things, and personal fulfilment at work. Finally, social support at work was measured by four items dealing with interaction with coworkers at work and outside work. The specific items are given in the appendix.

The WOM calculates separate mean estimates for each of 261 occupational groups in the Nordic occupational classification system. Within each of these three digit occupational title groups separate mean estimates were made for men and women, and for age groups $25-44$ and $\geqslant 45$. All WOM scores are transformed to a scale from $0-10$, with a score of 10 indicating high psychological demands, high decision latitude, and high social support at work. Each subject in this study was assigned a particular WOM score, based on occupation, sex, and age.

In the present study, cases and controls could be classified into the three different work environment factors of interest with the WOM through the occupational title obtained from the two censuses. Thus, exposure could be assessed at two points (1970 and 1975). The definitions of occupations in WOM were almost identical in the 1970 and 1975 censuses. Because of certain minor differences a few cases and controls were excluded.

In the analyses, two approaches were used to categorise psychological demands, decision latitude, and social support at work. These approaches were (a) a division into four categories with quartile scores for cases and controls combined as a cut off point, and $(b)$ a dichotomisation at the median scores. The results from these two approaches were very similar, and we report only the results from analyses with the dichotomisation as this gave better statistical precision.

High job strain was defined as a combination of high psychological demands and low decision latitude in accordance with the KarasekTheorell model. Thus, exposure to high job strain corresponded with a score above the median on psychological demands and also a score below the median on decision latitude. In the analyses of job strain, subjects in occupations characterised by high psychological demands and low decision latitude (high strain), high psychological demands and high decision latitude (active), low psychological demands and low decision latitude (passive) were compared with subjects in occupations characterised by low psychological demands and high decision latitude (low strain).

The analyses were based on those people who belonged to the same exposure category (defined above) both in 1970 and in 1975. The number of cases and controls varied between the different analyses. Altogether, 10008 cases of first myocardial infarction (8833 men and 1175 women) and 28448 controls (24 913 men and 3535 women) were included in at least one of the analyses (table 1). 
Table 3 Relative risk (RR) for a first myocardial infarction for subjects in occupations characterised by active, passive, and high strain psychosocial work environments compared with subjects in occupations characterised by a low strain work environment

\begin{tabular}{|c|c|c|c|c|}
\hline \multirow[b]{2}{*}{ Occupation type } & \multicolumn{2}{|l|}{ Men } & \multicolumn{2}{|c|}{ Women } \\
\hline & $R R^{\star}$ & $(95 \% C I)$ & $R R$ & $(95 \% C I)$ \\
\hline Low strain & 1.00 & - & 1.00 & - \\
\hline Active & 0.89 & (0.81 to 0.98$)$ & 0.93 & (0.75 to 1.16$)$ \\
\hline Passive & 1.04 & (0.94 to 1.14$)$ & 1.43 & (1.13 to 1.81$)$ \\
\hline High strain & 1.21 & (1.08 to 1.35$)$ & 1.23 & (1.01 to 1.51$)$ \\
\hline
\end{tabular}

${ }^{\star} \mathrm{RR}$ adjusted for age, county of residence, and calendar year.

Table 4 Relative risk (RR) for a first myocardial infarction for subjects in occupations characterised by combinations of decision latitude and social support at work compared with subjects in occupations characterised by high desicion latitude and high social support at work

\begin{tabular}{|c|c|c|c|c|c|}
\hline \multicolumn{2}{|c|}{ Occupation type } & \multicolumn{2}{|l|}{ Men } & \multicolumn{2}{|c|}{ Women } \\
\hline $\begin{array}{l}\text { Decision } \\
\text { latitude }\end{array}$ & $\begin{array}{l}\text { Social support } \\
\text { at work }\end{array}$ & $R R^{\star}$ & $(95 \% C I)$ & $R R$ & $(95 \% C I)$ \\
\hline High & High & 1.00 & - & 1.00 & - \\
\hline High & Low & 1.02 & (0.94 to 1.10$)$ & 1.21 & (0.96 to 1.53 ) \\
\hline Low & High & 1.05 & (0.96 to 1.16$)$ & 1.43 & (1.16 to 1.77 ) \\
\hline Low & Low & 1.24 & (1.17 to 1.33$)$ & 1.56 & ( 1.28 to 1.91$)$ \\
\hline
\end{tabular}

${ }^{\star} \mathrm{RR}$ adjusted for age, county of residence, and calendar year.

STATISTICAL METHODS

Odds ratios (ORs) were computed to estimate the relative risk (incidence density ratio; $\mathrm{RR}$ ) of a first myocardial infarction for subjects in a certain exposure category, compared with subjects in a reference category. To control for confounding from age (5-year age groups), county of residence, calendar year, socioeconomic group and work environment factors, we used stratified analyses in accordance with the Mantel-Haenszel method ${ }^{24} ; 95 \%$ confidence intervals (95\% CIs) were computed in accordance with methods suggested by Robins et al. ${ }^{25}$

\section{Results}

A higher incidence of myocardial infarction was found among subjects in occupations characterised by low decision latitude than in subjects in occupations with high decision latitude (table 2). This increase was present among men as well as among women. Subjects

Table 5 Relative risk (RR) for a first myocardial infarction for subjects in occupations characterised by low* decision latitude, high psychological demands, and low social support at work compared with subjects in occupations characterised by high decision latitude, low psychological demands, and high social support at work, and for subjects in occupations characterised by active, passive, and high strain psychosocial work environment compared with subjects in occupations characterised by low strain work (men 30-54 and 55-64 years old)

\begin{tabular}{|c|c|c|c|c|}
\hline \multirow[b]{2}{*}{ Work environment factor } & \multicolumn{2}{|c|}{ Age 30-54 } & \multicolumn{2}{|c|}{ Age 55-64 } \\
\hline & $R R t$ & $(95 \% C I)$ & $R R$ & $(95 \% C I)$ \\
\hline \multicolumn{5}{|l|}{ Decision latitude: } \\
\hline High & 1.00 & - & 1.00 & - \\
\hline Low & 1.37 & (1.25 to 1.50$)$ & 1.12 & (1.05 to 1.19$)$ \\
\hline \multicolumn{5}{|l|}{ Psychological demands: } \\
\hline Low & 1.00 & - & 1.00 & - \\
\hline High & 0.93 & (0.84 to 1.02$)$ & 0.95 & (0.89 to 1.01$)$ \\
\hline \multicolumn{5}{|l|}{ Social support at work: } \\
\hline High & 1.00 & - & 1.00 & - \\
\hline Low & 1.28 & (1.17 to 1.41$)$ & 1.10 & (1.04 to 1.17$)$ \\
\hline \multicolumn{5}{|l|}{ Job strain model: } \\
\hline Low strain & 1.00 & - & 1.00 & - \\
\hline Active & 0.89 & (0.76 to 1.04$)$ & 0.90 & (0.80 to 1.00$)$ \\
\hline Passive & 1.16 & (0.97 to 1.38$)$ & 0.99 & (0.88 to 1.11$)$ \\
\hline High strain & 1.45 & (1.19 to 1.77$)$ & 1.11 & (0.97 to 1.27$)$ \\
\hline
\end{tabular}

${ }^{\star}$ Low defined as a score below the median for cases and controls combined, and high defined as a score above the median.

tRR adjusted for age, county of residence, and calendar year. in occupations with low social support at work had a higher incidence than subjects with high social support at work in both sexes. No increase in incidence was found for subjects in occupations characterised by high psychological demands.

In analyses of combinations of decision latitude and psychological demands according to the job strain model, an increase in incidence of about $20 \%$ was found in both sexes for subjects in occupations characterised by high strain work (high demands and low decision latitude) compared with subjects in low strain occupations (low demands and high decision latitude (table 3)). Among women there was also a higher incidence for subjects in occupations with passive work (low demands and low decision latitude). Active occupations (high demands and high decision latitude) were not associated with an increased incidence of myocardial infarction either among men or among women. In analyses controlling for age, county of residence, and socioeconomic group the associations between job strain and incidence of myocardial infarction were weaker. Among men the RR for subjects in high strain occupations compared with subjects in low strain occupations was 1.12 (95\% CI 0.99 to 1.27 ). Among women the corresponding RR was 1.09 (95\% CI 0.82-1.44).

Men as well as women in occupations characterised by a combination of low social support at work and low decision latitude had an increased incidence of myocardial infarction compared with subjects in occupations with high social support at work and high decision latitude (table 4). Controlling for socioeconomic group only slightly modified these associations: for men the RR was 1.13 (95\% CI 1.00 to 1.27 ) and for women the RR was 1.51 (1.01 to 2.27). The results for women suggested a lower incidence for subjects in occupations characterised by high decision latitude and high social support at work than women in other types of occupations.

It has been suggested that the relation between job strain and coronary heart disease may be modified by age. ${ }^{2}$ In this study we found that in high strain occupations men of 30 to 54 had a $45 \%$ higher incidence of myocardial infarction than men in low strain occupations (table 5). In men 55 to 64 years of age the corresponding increase was $11 \%$. Controlling in the analyses for socioeconomic group yielded an RR of 1.31 (95\% CI 1.03 to 1.65 ) for men 30-54 years of age and 1.05 (95\% CI 0.91 to 1.22 ) for men $55-64$ years of age. Also the RRs for low decision latitude and low social support at work were higher for younger than for older men. Notably, the steep increase in background incidence of myocardial infraction with increasing age will result in higher RRs among younger than among older men even when the differences in incidence are similar in the two age groups. In the mid-1990s men in Stockholm aged 55-64 had about five times the incidence of first myocardial infarction than men aged 30-54. Age specific analyses for women of associations between psychosocial work environment factors and incidence of 
Table 6 Relative risk (RR) for a first myocardial infarction among subjects characterised by combinations of psychological demands, decision latitude, and social support at work compared with subjects in occupations characterised by low psychological demands, high decision latitude, and high social support at work. Men (all and 30-54 y) and women

\begin{tabular}{|c|c|c|c|c|c|c|c|c|}
\hline \multirow{2}{*}{\multicolumn{3}{|c|}{ Occupation type }} & \multicolumn{4}{|l|}{ Men } & & \\
\hline & & & \multicolumn{2}{|l|}{$\overline{A l l}$} & \multicolumn{2}{|c|}{$30-54 y$} & \multicolumn{2}{|c|}{ Women } \\
\hline $\begin{array}{l}\text { Decision } \\
\text { latitude }\end{array}$ & $\begin{array}{l}\text { Psychological } \\
\text { demands }\end{array}$ & $\begin{array}{l}\text { Social } \\
\text { support }\end{array}$ & $R R^{\star}$ & $(95 \% C I)$ & $R R$ & $(95 \% C I)$ & $R R$ & $(95 \% C I)$ \\
\hline High & Low & High & 1.00 & - & 1.00 & - & 1.00 & - \\
\hline High & Low & Low & 1.17 & (0.98 to 1.39 ) & 1.29 & (0.94 to 1.77$)$ & 1.46 & (0.98 to 2.18$)$ \\
\hline High & High & High & 0.97 & (0.84 to 1.12 ) & 1.03 & (0.82 to 1.29$)$ & 0.91 & (0.68 to 1.22$)$ \\
\hline High & High & Low & 0.93 & (0.79 to 1.09 ) & 0.98 & (0.74 to 1.29$)$ & 1.04 & $(0.79$ to 1.36$)$ \\
\hline Low & Low & High & 1.04 & (0.89 to 1.23 ) & 1.26 & (0.95 to 1.66$)$ & 1.39 & (0.92 to 2.11$)$ \\
\hline Low & Low & Low & 1.17 & (1.01 to 1.36$)$ & 1.47 & ( 1.14 to 1.89$)$ & 1.49 & ( 1.14 to 1.94$)$ \\
\hline Low & High & High & 1.49 & (1.04 to 2.13$)$ & 1.57 & (0.79 to 3.13$)$ & 1.37 & (1.06 to 1.76$)$ \\
\hline Low & High & Low & 1.35 & (1.16 to 1.58$)$ & 1.82 & (1.41 to 2.34 ) & 1.31 & (0.99 to 1.73 ) \\
\hline
\end{tabular}

${ }^{\star} \mathrm{RR}$ adjusted for age and county of residence.

myocardial infarction were not meaningful in this study because of small numbers.

When social support at work was taken into account in the stratified analyses, the association between being in a high strain job and incidence of myocardial infarction was weaker among men. Among women the results were essentially unchanged (not shown in table). For all men the RR was 1.1 (95\% CI 1.0 to 1.3 ) and for men $30-54$ years of age 1.3 (1.0 to 1.7). The RR associated with low social support at work, controlling for psychological demands, and decision latitude was 1.1 for both men and women $(95 \%$ CI for men 1.0 to 1.2 , and for women 1.0 to 1.4$)$. Among younger men the corresponding RR was 1.2 (95\% CI 1.0 to 1.5).

Table 6 presents results where subjects in occupations characterised by different combinations of psychological demands, decision latitude, and social support at work were compared with subjects in occupations characterised by low demands, high decision latitude, and high social support at work. An increased incidence of myocardial infarction was found in both sexes, primarily for subjects in occupations characterised by low decision latitude. In analyses including all men, a higher incidence was found among subjects in occupations with high job strain, irrespective of the level of social support at work. Similar results were obtained for younger men and for women. For younger men in occupations with high job strain and low social support at work the RR was 1.82 . Controlling also for socioeconomic group in the analyses only marginally influenced this estimate (RR $1.79,95 \%$ CI 1.22 to 2.65 ). Men and women in passive occupations also had an increased incidence of myocardial infarction, particularly when combined with low social support at work. High decision latitude tended to be associated with a higher incidence only in combination with low demands and low social support at work. The occupation type characterised by high decision latitude, low psychological demands, and low social support at work was, however, dominated by building caretakers, and previous studies have indicated that there may be a selection into this occupation of subjects in poor health. ${ }^{26}$

\section{Discussion}

A high incidence of first acute myocardial infarction among men and women in occupations characterised by low decision latitude was found in this study. The results indicate that for men a low decision latitude primarily in combination with high psychological demands (high job strain) and low social support at work may increase the risk of acute myocardial infarction.

The results of this study may have been influenced by misclassification of exposure and disease respectively. A misclassification of occupation could be due to false answers in the censuses, coding errors, or errors in the linkage of census information to cases and controls. We used information about occupation from two consecutive censuses, thus the misclassification of occupation was probably small. Furthermore, as information about occupation was obtained from before the observation period, it is likely that any misclassification of occupation was unrelated to subsequent myocardial infarction.

Factors of the psychosocial work environment were measured retrospectively for a large study base with a work organisation exposure matrix. It has been suggested that a work exposure matrix may have the advantage over individual self reports in that it may reduce possible bias due to the person's perception of the work environment. ${ }^{22}$ The individual perception may be subject to changes that are influenced by factors irrelevant to the exposure assessment. In this situation the average exposure as perceived by a large group of workers may give a better exposure assessment than individual self reports. However, the use of an exposure matrix introduces a misclassification of exposure for individual people as a job title may be associated with several different work environment conditions. There may also have been a misclassification on the aggregate level because the exposure matrix was developed on the basis of information from subjects other than those included in this study.

Based on a previous evaluation of the WOM in which individual self reports were compared with the matrix scores, it seems likely that the exposure assessment was better for decision latitude than for psychological demands and 
social support at work. ${ }^{22}$ A good correlation between self reports and matrix scores was found for decision latitude, but for social support at work and for psychological demands the correlations were weak. This suggests that within occupations variability for social support at work and psychological demands was not well captured by the matrix. It is likely that the misclassification of exposure was nondifferential, and this may in part explain some of the weak associations between psychological demands and social support at work to incidence of myocardial infarction in this study.

In the Western Electric study an increased mortality from coronary heart disease for subjects in high strain occupations was found in analyses where several risk factors, including smoking, blood pressure, and serum cholesterol were taken into account, but not when controlling for occupational class. ${ }^{10}$ In the present study we found, in general, weaker associations when controlling for socioeconomic group, and among women the association between job strain and incidence of myocardial infarction was not significant in these analyses. These findings could be due to reduced confounding when controlling for socioeconomic group or to smaller actual contrasts in exposure within socioeconomic groups, or both. We found that for decision latitude and for psychological demands the exposure contrasts, measured as the mean difference between the third and the first quartile scores, were smaller in analyses of blue collar workers separately than in analyses of all employed workers. However, for social support at work we found no difference in this respect between all employed workers and blue collar workers. This would indicate that reduced exposure contrasts may have contributed to the lower RR estimates in the analyses controlling for socioeconomic group.

In the present study, cases of myocardial infarction were identified through registers. There is practically no loss of deaths in the National Cause of Death Register and the hospital discharge registers covered all hospitals treating acute medical cases in the study areas. The study covered more than 10000 cases, and it was not possible to control the diagnostic information for all of these. However, 381 randomly selected cases were included in a previous validation study. ${ }^{27}$ Analyses of this group indicated that the proportions not fulfilling strict criteria for acute myocardial infarction were similar ( $<5 \%$ differences) in comparisons of cases in occupations characterised by high $v$ low psychological job demands, high $v$ low decision latitude, and high $v$ low social support at work. This indicates a basically nondifferential misclassification of disease which would tend to dilute actual associations.

It has been noted that many infarctions are silent and do not reach medical attention. ${ }^{28}$ For obvious reasons silent cases could not be included in this study. The proportion of silent cases may be related to the propensity to seek medical care or to the frequency of health examinations. If there were differences of this type between the occupational groups that we compared this may have biased our results.

We included only subjects with the same type of occupation in both 1970 and 1975 . Therefore, any health related selection into the occupation must have occurred at least five years before the observation period. This would reduce the risk of a bias due to a health related selection into the type of occupation. However, health selection may still be a problem in this study. For example, the higher incidence found for subjects in occupations characterised by low psychological demands, high decision latitude, and low social support at work, predominantly building caretakers, was most likely due to health selection. ${ }^{26}$

The present study was based on data from registers which allowed a large study base. The period covered was 1976-84 and there may have been changes in the work environment in Sweden since that period that could influence the relevance of our results. However, in a recent population based case-control study in Stockholm covering the period 1992-4 similar results were reported for the association between job strain and incidence of myocardial infarction. $^{29}$ This would indicate that the results of the present study would not be notably different, at least for job strain, if the study was repeated with more recent data.

An important shortcoming of this study was that the registers that were used in the data collection did not contain information on several potentially confounding factors. It is possible that differences in smoking habits, dietary habits, physical activity, or other factors may have been of importance for the associations found between factors of the psychosocial work environment and incidence of myocardial infarction. However, in some previous studies $^{5710}$ the association between job strain and incidence of myocardial infarction or mortality from coronary heart disease has remained after controlling for the main risk factors of coronary heart disease. In the recent Swedish case-control study, self reported job strain was associated with a $40 \%$ increase in the incidence of first myocardial infarction (95\% CI 1.0 to 1.8 ) after controlling for age, smoking, and several biomedical risk factors for coronary heart disease. ${ }^{29}$ If the associations between factors of the psychosocial work environment and incidence of myocardial infarction found in the present study are causal, they may be of importance from the point of view of workers' health. The methods used for exposure assessment in this study were crude and may well have contributed to underestimates of actual associations. It is our view that further studies are needed in this area-studies with improved methods and with information that can permit analyses of possible interaction with other risk factors for myocardial infarction as well as of possible biological mechanisms.

We thank Ms Gunnel Gråbergs for computer assistance. The study was supported by grant number $91-1368$ from the Swedish Work Environment Fund. 


\section{Appendix: Specific items used in the work organisation matrix to measure psychosocial work environment} PSYCHOLOGICAL JOB DEMANDS

Is your job hectic?

Is your job psychologically demanding?

DECISION LATITUDE

The subject stated whether they never, sometimes, or often had any of the following:

Influence over the planning of work

Influence over the setting of the work pace

Influence over how time is used in work

Influence over the selection of supervisor

Influence over the selection of coworkers

Influence over the planning of work breaks

Influence over the planning of vacations

Flexible working hours

Varied task content

Varied work procedures

The possibility to learn new things

The experience of personal fulfillment on the job.

SOCIAL SUPPORT AT WORK

Can you talk to coworkers during breaks?

Can you leave the job to talk to coworkers?

Can you interact with coworkers as part of your work?

Do you see and spend some hours with fellow workers or colleagues outside of work?

1 Karasek RA. Job demands, job decision latitude and mental strain: implications for job redesign. Adm Sci $Q$ 1979;24:285-308

2 Schnall PL, Landsbergis PA, Baker D. Job strain and cardiovascular disease. Ann Rev Public Health 1994;15: cardiovas 381 .

3 Karasek RA, Baker D, Marxer F, et al. Job decision latitude, job demands, and cardiovascular disease: a prospective job demands, and cardiovascular disease: a prospective
study of Swedish men. Am $\mathcal{F}$ Public Health 1981;71:694study

4 Alfredsson L, Theorell T. Job characteristics of occupations and myocardial infarction risk: effect of possible confounding factors. Soc Sci Med 1983;17:1497-503.

$5 \mathrm{La}$ Croix A, Haynes S. Occupational exposure to high demand/low control work and coronary heart disease in the Framingham cohort. Am f Epidemiol 1984;120:481.

6 Alfredsson L, Spetz CL, Theorell T. Type of occupation and near-future hospitalization for myocardial infarction an some other diagnoses. Int $\mathcal{F}$ Epidemiol 1985;14:378-88.

7 Haan M. Job strain and cardiovascular disease. A ten-year prospective study. Am F Epidemiol 1985;122:532.

8 Karasek RA, Theorell T, Schwartz J, et al. Job characteristics in relation to the prevalence of myocardial infarction in the US HES and HANES. Am f Public Health 1988;78:910-8.
9 Reed DM, La Croix AZ, Karasek RA, et al. Occupational Reed DM, La Croix AZ, Karasek RA, et al. Occupational strain and the incidence of cor

10 Alterman T, Shekelle RB, Vernon SW, et al. Decision latitude, psychological demand, job strain, and coronary heart disease in the Western Electric study. Am f Epidemiol 1994;139:620-7.

11 Hammar N, Alfredsson L, Theorell T. Job characteristics and the incidence of myocardial infarction. Int $\mathcal{F}$ Epidemiol 1994;23:277-84.

12 Steenland K, Johnson J, Nowlin S. A follow-up study of job strain and heart disease among males in the NHANES1 population. Am f Ind Med 1997;31:256-9.

13 Johnson JV, Hall EM. Job strain, work place social support, and cardiovascular disease: a cross-sectional study of a random sample of the Swedish working population. Am $\mathcal{F}$ Public Health 1988;78:1336-42.

14 Johnson J, Hall EM, Theorell T. Combined effect of job strain and social isolation and cardiovascular disease morbidity and mortality in a random sample of the Swedish male working population. Scand $f$ Work Environ Health 1989;15:271-9.

15 Johnson JV, Stewart W, Hall EM, et al. Long term psychosocial work environment and cardiovascular mortality amon Swedish men. Am f Public Health 1996;86:324-31.

16 Ahlbom A. Acute myocardial infarction in Stockholm: a medical information system as an epidemiological tool. Int f Epidemiol 1978;7:271-6.

17 Hammar N, Nerbrand C, Ahlmark G, et al. Identification of cases of myocardial infarction: hospital discharge data and mortality data compared with myocardial infarction registers. Int F Epidemiol 1991;20:114-20.

18 Statistics Sweden. Rapport i samordningsfrågor (Report on statistical co-ordination). Stockholm: Statistics Sweden, 1982:4.

19 Hammar N, Alfredsson L, Smedberg M, et al. Differences in the incidence of myocardial infarction among occupational the incidence of myocardial infarction among occupation

20 Johnson JV, Stewart W, Fredlund P, et al. Psychosocial job exposure matrix: an occupationally aggregated attribution system for work environment exposure characteristics. Stockholm: Karolinska Institute. Department of Stress Research. 1990. (Stress research reports 221.)

21 Theorell T, de Faire U, Johnson J, et al. Job strain and ambulatory blood pressure profiles. Scand $\mathcal{F}$ Work Environ Health 1991;17:380-5.

22 Johnson JV, Stewart WF. Measuring work organization exposure over the life course with a job-exposure matrix. Scand f Work Environ Health 1993;19:21-8.

23 Hall EM, Johnson JV, Tsou TS. Women, occupation and risk of cardiovascular morbidity and mortality. Occup Med State Art Rev 1993;8:1-11.

24 Mantel N, Haenszel W. Statistical aspects of the analysis of data from retrospective studies of disease. 7 Natl Cancer Inst 1959;22:719-48.

25 Robins J, Greenland S, Breslow NE. A general estimator for the variance of the Mantel-Haenszel odds ratio. Am $7 \mathrm{Epi}$ demiol 1986;124:719-23.

26 Östlin P. Occupational career and health: methodological considerations on the healthy worker effect [thesis]. Uppsala, Sweden: University of Uppsala, 1989.

27 Hammar N, Larsen FF, de Faire U. Are geographical differences and time trends in myocardial infarction incidence in Sweden real? Validity of hospital discharge diagnoses. $\mathcal{F}$ Clin Epidemiol 1994;47:685-93

28 Kannnel WB, Abbot RD. Incidence and prognosis of unrecognized myocardial infarction. $N$ Engl 7 Med 1984;311: 1144-7.

29 Theorell T, Tsutsumi A, Hallquist J, et al. Decision latitude, job strain, and myocardial infarction. A study of working men in Stockholm (Stockholm . A study of working Program, SHEEP). Am f Publ Health 1988;88:382-8. 